\title{
IDENTIFICACIÓN DE ESPECIES DE Fusarium AISLADAS DE SEMILLAS SINTOMÁTICAS Y ASINTOMÁTICAS DE MAÍZ CON BASE EN EL GEN TEF-1a
}

\author{
IDENTIFICATION OF Fusarium SPECIES ISOLATED FROM SYMPTOMATIC \\ AND ASYMPTOMATIC MAIZE SEEDS BASED ON THE TEF-1a GENE
}

\author{
Teresa B. Uribe-Cortés ${ }^{1}$, Hilda V. Silva-Rojas ${ }^{1}{ }^{*}$ Leopoldo E. Mendoza-Onofre ${ }^{1}$, \\ Carmen Velázquez-Cruz ${ }^{2}$ y Ángel Rebollar-Alviter ${ }^{3}$
}

\begin{abstract}
'Colegio de Postgraduados, Campus Montecillo, PREGEP-Producción de Semillas, Montecillo, Texcoco, Estado de México, México. ²Dupont Pioneer, Centro de Investigación Tlajomulco, Tlajomulco de Zúñiga, Jalisco, México. ${ }^{3}$ Universidad Autónoma Chapingo, Centro Regional Universitario Centro Occidente, Morelia, Michoacán, México.
\end{abstract}

*Autor de correspondencia (hsilva@colpos.mx)

\section{RESUMEN}

Un problema fitosanitario en el cultivo de maíz (Zea mays L.) es la pudrición de mazorca a causa de hongos del complejo Fusarium fujikuroi. El síntoma típico de la enfermedad es la presencia de semillas con pudrición distribuidas aleatoriamente en la mazorca. Con frecuencia, el fitomejorador selecciona plantas con mazorcas sanas, que en ocasiones contienen pocas semillas con síntomas y suponen que las semillas asintomáticas están libres del patógeno. El objetivo del presente estudio fue identificar especies de Fusarium tanto en semillas sintomáticas como asintomáticas procedentes de la misma mazorca con base en la filogenia de una región del factor de elongación de la traducción 1a (TEF-1a). Se utilizaron mazorcas de lotes de producción de semilla ubicados en 14 localidades de cinco entidades federativas de México; 28 mazorcas de Chiapas, 16 de Chihuahua, 10 de Guanajuato, 14 del Estado de México y 16 de Jalisco. Las semillas de cada tipo se desinfestaron y se colocaron en medio de cultivo. Después de $5 \mathrm{~d}$ se observó crecimiento del micelio y de conidios, de los cuales se seleccionaron tres por cada aislamiento, se transfirieron a medio PDA y se registró su coloración (blanco, salmón, morado, violeta o rojo). Se obtuvieron 439 cepas. El color predominante de los micelios fue el blanco. El $54 \%$ del total de cepas provino de semillas sintomáticas y el resto de asintomáticas. En cada estado, el número de cepas procedente de cada tipo de semillas fue similar. En ambos casos se identificó a Fusarium subglutinans, F. temperatum y F. verticillioides; además, por primera vez en México se detectó la presencia de los Haplotipos 10 y 11 de esta última especie. El fitomejorador corre el riesgo de seleccionar germoplasma susceptible a la pudrición cuando elige plantas que producen mazorcas en las que coexisten ambos tipos de semilla.

Palabras clave: Fusarium verticillioides, filogenia, haplotipos, pudrición de mazorca, semillas.

\section{SUMMARY}

A phytosanitary problem in maize (Zea mays L.) is ear rotting due to fungi belonging to the Fusarium fujikuroi complex. The typical symptom of the disease is the presence of rotten seeds randomly distributed on the ear. Frequently, the plant breeder selects plants that produce healthy ears, which sometimes contain a few seeds with symptoms, assuming that the asymptomatic seeds are free of the pathogen. The objective of the present study was to identify Fusarium species in both symptomatic and asymptomatic seeds from the same ear, based on the phylogeny of a region of the $1 a$ translation elongation factor (TEF-1a). Ears from seed production plots from 14 locations of five states of Mexico were used: 28 ears from Chiapas, 16 from Chihuahua, 10 from Guanajuato, 14 from the State of Mexico and 16 from Jalisco. Seeds of each type were disinfested and placed in culture medium. After $5 \mathrm{~d}$ mycelium and conidia growth was observed, of which three were selected from each isolate, transferred to PDA medium and their coloration (white, salmon, purple, violet or red) was registered. Four hundred and thirtynine strains were obtained. The predominant color of the mycelia was white. Fifty-four percent of the total strains came from symptomatic seeds and the rest from asymptomatic ones. In each state, the number of strains from each type of seed was similar. In both cases, Fusarium subglutinans, F. temperatum and $F$. verticillioides were identified. In addition, for the first time in Mexico, the presence of Haplotypes 10 and 11 of the latter species was detected. The breeder is at the risk of selecting germplasm susceptible to rot when choosing plants that produce ears in which both types of seed coexist.

Index words: Ear rot, Fusarium verticillioides, haplotypes, phylogeny, seeds.

\section{INTRODUCCIÓN}

El maíz (Zea mays L.) es el tercer cereal más importante para la alimentación en el mundo, después del arroz (Oryza sativa L.) y el trigo (Triticum aestivum L.). Su producción se destina principalmente a la alimentación humana y animal, y en las últimas dos décadas se ha convertido en un insumo útil para la producción de biocombustible (Young y Long, 2000).

México ocupa el sexto lugar en producción mundial y el tercero en América Latina y el Caribe (FAOSTAT, 2017). En el año 2016, el 38 \% de la superficie agrícola total en México se sembró con maíz; la mayor proporción de esta superficie se encuentra en zonas de secano. Los principales estados productores son Sinaloa, Jalisco, Estado de México, Michoacán y Guanajuato (SIAP, 2016).

La pudrición de mazorca reduce el rendimiento del cultivo (Briones-Reyes et al., 2015; Leyva-Madrigal et al., 2015). Los agentes causales de esta pudrición 
corresponden al denominado complejo Fusarium fujikuroi que incluye al menos 50 especies filogenéticas que se caracterizan por producir diversos tipos de toxinas como fumonisinas, tricotecenos, moniliformina y beauvericina (O'Donnell et al., 2018). En los maíces susceptibles, las especies que se encuentran con mayor frecuencia son: F. verticillioides (Saccardo) Nirenberg, F. subglutinans (Wollenweber y Raeinking) P. E. Nelson, Toussoun y Marasas y F. proliferatum (Matsushima) Nirenberg (O'Donnell et al., 2000). Estas especies causan pudrición de semilla, marchitamiento, reducción de la germinación, pudrición de raíces y tallos, así como tizón en plántulas (Leslie y Summerell, 2013).

En México, la pudrición de mazorca se ha reportado en los Valles Altos Centrales (Morales-Rodríguez et al., 2007), donde se han detectado altos niveles de resistencia en híbridos experimentales de maíz, como el HGVC-2 (Rivas-Valencia et al., 2011). La enfermedad también está presente en los estados de Tamaulipas, Jalisco, Veracruz, Chiapas, Sonora (Leyva-Madrigal et al., 2015) y Oaxaca (Briones-Reyes et al., 2015).

Algunas cepas de $F$. verticillioides producen infecciones asintomáticas en la semilla, donde se ha demostrado que inicialmente el hongo invade el tejido en desarrollo (Wigmann et al., 2019) y posteriormente causa una infección sistémica en la planta (Mancini et al., 2016); por esto, la certificación de la calidad fitosanitaria de las semillas es un requisito esencial en la industria semillera.

El diagnóstico temprano de patógenos fúngicos que se transmiten vía semillas sintomáticas es trascendental, pues este insumo es la unidad básica de producción y un componente primario del comercio semillero. Semillas asintomáticas también pueden ser portadoras de patógenos, los que en condiciones ambientales favorables logran establecerse en áreas donde han estado ausentes (Tsedaley, 2015). En consecuencia, las medidas de protección para evitar la diseminación de la enfermedad, - para reducir su presencia, se basan inicialmente en la detección e identificación precisa de los patógenos (Walcott, 2003); por el contrario, una identificación imprecisa puede conducir a medidas innecesarias de control, como la aplicación de restricciones cuarentenarias inoportunas, o paradójicamente, a omitir alguna acción para controlar patógenos potencialmente devastadores (Crous et al., 2015).

En la identificación molecular de Fusarium spp., el factor de elongación de la traducción 1a (TEF-1a) es uno de los genes unicopia más útiles para discriminar especies del mismo género mediante estudios filogenéticos (Karlsson et al., 2016). Este gen es rico en exones (Geiser, 2004) y se caracteriza por i) ser altamente informativo a nivel de especie, ii) no haberse detectado individuos no ortólogos del gen en el género y iii) existen bases de datos extensas con las que se pueden comparar las secuencias; además, estos genes muestran una tendencia a evolucionar a un ritmo mayor que el de la región correspondiente al espacio transcrito interno (ITS) del rDNA que es un operón multicopia (O'Donnell et al., 2000). Actualmente la descripción de al menos 50 especies que conforman el complejo F. fujikuroi y las bases de datos para la reconstrucción filogenética de nuevos aislamientos se basan principalmente en la información del gen TEF (Geiser et al., 2004; O'Donnell et al., 2015), que es una proteína compleja involucrada en el movimiento de los tRNAs con el aminoácido dentro del ribosoma para la síntesis de la cadena polipeptídica (Raja et al., 2017).

En el proceso de selección de germoplasma de maíz tolerante a la pudrición de mazorca se generan líneas segregantes cuyas mazorcas contienen semillas sintomáticas y asintomáticas; particularmente al inicio de la derivación de líneas o de familias, el fitomejorador selecciona aquellas cuyas mazorcas contienen la mayor proporción de semillas asintomáticas, aunque las semillas vecinas muestren síntomas de la enfermedad; en consecuencia, es necesario dilucidar las especies de Fusarium y la frecuencia con que éstas se presentan en ambos tipos de semilla.

El objetivo del presente estudio fue verificar la presencia de especies de Fusarium del complejo F. fujikuroi aisladas de semillas sintomáticas y asintomáticas procedentes de mazorcas enfermas e identificar las especies con base en la amplificación de la secuencia parcial del gen TEF-7a.

\section{MATERIALES Y MÉTODOS}

\section{Material genético}

Se utilizaron 84 mazorcas que procedían de programas de mejoramiento genético para resistencia a pudrición de mazorca cosechadas en el ciclo otoño-invierno 2015, las que se conservaron en un cuarto frío a $-10{ }^{\circ} \mathrm{C}$ hasta su análisis. Cada mazorca contenía semillas sintomáticas y asintomáticas procedentes de lotes de producción de semilla ubicados en 14 localidades pertenecientes a cinco entidades federativas de México. Se analizaron 28 mazorcas de Chiapas, 16 de Chihuahua, 14 del Estado de México, 10 de Guanajuato y 16 de Jalisco.

\section{Aislamientos y obtención de cultivos monoconidiales}

De cada mazorca se seleccionaron 10 semillas sintomáticas y 10 asintomáticas, las cuales se 
desinfestaron con una solución de hipoclorito de sodio ( $\mathrm{NaClO}$ ) 1.5\% y se enjuagaron dos veces con agua destilada estéril; después, se cubrieron con papel filtro estéril y se colocaron a temperatura ambiente para eliminar el exceso de humedad. Posteriormente, cada grupo de 10 semillas se colocó en una caja de Petri que contenía medio de cultivo semiselectivo Spezieller-Nährstffarmer-Agar (SNA) $\left(1 \mathrm{~g} \mathrm{KH}_{2} \mathrm{PO}_{4^{\prime}} 1 \mathrm{~g} \mathrm{KNO}_{3^{\prime}} 0.5 \mathrm{~g} \mathrm{MgSO}_{4} \cdot 7 \mathrm{H}_{2} \mathrm{O}, 0.5 \mathrm{~g} \mathrm{KCl}, 0.2 \mathrm{~g}\right.$ dextrosa, $0.2 \mathrm{~g}$ sacarosa y $20 \mathrm{~g}$ agar) (Leslie y Summerell, 2006). Las cajas Petri se colocaron en una cámara de crecimiento a $23^{\circ} \mathrm{C}$ por $5 \mathrm{~d}$; posteriormente, una sección del micelio de cada caja se colocó en un tubo Eppendorf de $1.5 \mathrm{~mL}$ con agua destilada y Tween 20 0.5\%. Los tubos se mezclaron por inversión y $100 \mu \mathrm{L}$ de la suspensión se transfirió a un nuevo tubo con $900 \mu \mathrm{L}$ de agua con Tween 200.1 \% para obtener diluciones seriadas. De las diluciones $10^{-1}$ y $10^{-2}$ se transfirieron $120 \mu \mathrm{L}$, por separado, en cajas Petri con medio agar-agua (AA) (18 g de agar, $1000 \mathrm{~mL}$ de agua destilada) para germinar los conidios. Transcurridas $12 \mathrm{~h}$, se realizó la micro-manipulación bajo un estereoscopio para seleccionar tres conidios germinados, los que se colocaron por separado en cajas con medio papa-dextrosa-agar (PDA) (20 g de PDA, $2 \mathrm{~g}$ de agar). A los 8 d se registró el color del micelio (blanco, morado, salmón, violeta o rojo) que se desarrolló sobre las semillas. Al final del proceso se obtuvieron 439 cultivos monoconidiales (cepas); cada cepa se conservó en papel filtro Wathman \#1 (GE Healthcare, Chicago, Illinois, EUA) cubierto con papel aluminio a $4{ }^{\circ} \mathrm{C}$ dentro de un recipiente hermético.

\section{Extracción de DNA de las cepas aisladas}

Las cepas se reactivaron en medio SNA; después de 8 d se colectó el micelio con una espátula y se colocó en un tubo Eppendorf de $2 \mathrm{~mL}$. La extracción de DNA se basó en una modificación al protocolo de Bromuro de cetil-trimetil-amonio (CTAB) $2 \%$ propuesto por Doyle y Doyle (1990), que consistió en re-suspender la pastilla de DNA en $400 \mu \mathrm{L}$ de agua HPLC. Los tubos se incubaron a $55{ }^{\circ} \mathrm{C}$ por $15 \mathrm{~min}$; posteriormente, se agregaron $34 \mu \mathrm{L}$ de acetato de sodio $\left(\mathrm{C}_{2} \mathrm{H}_{3} \mathrm{NaO}_{2}\right) 3 \mathrm{M}$ y $1 \mathrm{~mL}$ de etanol $95 \%$ frío y éstos se mezclaron suavemente por inversión; los tubos se colocaron a $-20^{\circ} \mathrm{C}$ durante 1 h y se centrifugaron a $11,500 \times g$ por $5 \mathrm{~min}$. La pastilla se lavó dos veces con $650 \mu \mathrm{L}$ de etanol $70 \%$ y se centrifugó por $5 \mathrm{~min}$. Finalmente, la pastilla se re-suspendió en $40 \mu \mathrm{L}$ de agua HPLC y se almacenó a $-20{ }^{\circ} \mathrm{C}$. El DNA se cuantificó por espectrofotometría en un NanoDrop 2000 UV-Vis (Thermo Scientific, Waltham, Massachusetts, EUA) y se consideró de buena calidad cuando los valores de absorbancia de las relaciones $A_{260} / A_{280}$ y $A_{260} / A_{230}$, se encontraron entre $1.8 \mathrm{y}$ 2.0. Para la reacción en cadena de la polimerasa (PCR) el DNA se prepararó en diluciones de $20 \mathrm{ng} \mathrm{mL}^{-1}$.

\section{Amplificación y secuenciación del gen TEF-1a}

$\begin{array}{ccc}\text { Para la amplificación del gen } & \text { TEF- } \\ 1 a^{2} \text { se utilizaron los iniciadores } & \text { EF-448 }\end{array}$
(5'-TCACTTGATCTACAAGTGCGGTGG-3') y EF-1251 (5'-CCTCGAACTCACCAGTACCG-3'), que amplifican un fragmento de 650 pares de bases (pb) (Alves et al., 2008). La mezcla de reacción de PCR se preparó en un volumen final de $15 \mu \mathrm{L}$ que contenía agua HPLC, $1 \mathrm{X}$ buffer, $0.2 \mu \mathrm{M}$ de dNTPs, 10 pmol de cada iniciador, $0.9 \cup$ Go Taq DNA Polimerasa (Promega, Madison, Wisconsin, EUA) y $60 \mathrm{ng}$ de DNA. Las condiciones de amplificación consistieron en una desnaturalización inicial a $95^{\circ} \mathrm{C}$ por $85 \mathrm{~s}$, seguida por 35 ciclos de $95^{\circ} \mathrm{C}$ por $35 \mathrm{~s}, 60^{\circ} \mathrm{C}$ por $55 \mathrm{~s}$ y $72^{\circ} \mathrm{C}$ por 1.5 min, y un ciclo de extensión final a $72{ }^{\circ} \mathrm{C}$ por $10 \mathrm{~min}$. La reacción de PCR se llevó a cabo en un termociclador Peltier Thermal Cycler C1000 Touch ${ }^{\mathrm{TM}}$ (Bio-Rad, Hercules, California, EUA).

La amplificación de los productos de PCR se verificaron por electroforesis en gel de agarosa Seakem ${ }^{\circledR}$ (Lonza, Alpharetta, Georgia, EUA) 1.5\% teñido con GelRed®(Biotium, Fremont, California, EUA) y corrido a $80 \mathrm{~V}$ durante $1.5 \mathrm{~h}$. Las bandas se visualizaron en un transiluminador (Vilver Lourmat, Eberhardzell, Alemania) y se documentaron con el sistema Infinity (http://www.vilber.de/en/products/geldocumentation/infinity/). Los amplicones se limpiaron con el método enzimático ExoSAP-IT ${ }^{\mathrm{TM}}$ (Affymetrix, Santa Clara, California, EUA), de acuerdo con las instrucciones del fabricante.

La reacción de secuenciación se realizó en placas MicroAmp Optical de 96 pozos con el BigDye ${ }^{\mathrm{TM}}$ Terminator v 3.0 (Applied Biosystems ${ }^{\circledR}$, Foster City, California, EUA), en un volumen total de $20 \mu \mathrm{L}$ que contenía $4.0 \mu \mathrm{L}(2.5 \mathrm{X})$ de Ready Reaction Premix, $2.0 \mu \mathrm{L}$ (5X) BigDye sequencing buffer, 4 pM de cada iniciador y $2.0 \mu \mathrm{L}$ del producto de PCR como molde. Las placas se lavaron con el método de precipitación con acetato de sodio/etanol; posteriormente, se secaron e hidrataron con formamida. Finalmente, las placas se colocaron en un secuenciador Genetic Analyzer modelo 3130 (Applied Biosystems ${ }^{\circledR}$ ).

\section{Reconstrucción filogenética mediante inferencia bayesiana}

Las secuencias se ensamblaron con el programa bioinformático DNA Baser Sequence Assembler 4.36 (www.DnaBaser.com) para obtener la secuencia consenso correspondiente a cada cepa, las que se compararon con la opción Basic Local Alignment Search Tools Nucleotide (BLASTN) (Zhang et al., 2000) del National Center for Biotechnology Information (NCBI) (https://www.ncbi.nlm. 
nih.gov/) para determinar las secuencias relacionadas con base en los porcentajes de máxima identidad. De esta manera se identificaron las secuencias de referencia a incluirse para el análisis conjunto, las que se obtuvieron de la base de datos del Fungal Biodiversity Center's Fusarium Multilocus Sequence Typing (http://www.cbs.knaw.nl/ Fusarium) y del GenBank.

Para la reconstrucción filogenética, las secuencias consenso junto con las secuencias de referencia se compilaron en un archivo Fasta y se alinearon con la opción Muscle (Edgar, 2004), incluido en el programa MEGA 7 (Kumar et al., 2016) con los parámetros por defecto.

El árbol filogenético se construyó con el método de inferencia bayesiana con el programa MrBayes v.3.2 (Ronquist et al., 2012). Para el análisis se utilizó el modelo de sustitución nucleotídica Generalized Time Reversible (GTR), que considera que las tasas de sustitución, transiciones y transversiones son diferentes; además, el modelo incorpora diferentes tasas para cada cambio y diferente frecuencia de nucleótidos. En el presente estudio, el valor supuesto de cuatro caracteres implementado por defecto en el programa MrBayes se reemplazó por el valor de 6, que es la tasa de sustitución con la opción Iset (Tavaré, 1986); el muestreo de los árboles se realizó cada 1000 generaciones. El análisis concluyó cuando la desviación estándar fue menor que 0.01. Del total de árboles que se generó se eliminó el 25 \% con la función burn-in phase; la probabilidad posterior se determinó con el resto de los árboles. La visualización del árbol se realizó con el programa FigTree (http://tree.bio.ed.ac.uk/software/ figtree/) y las secuencias resultantes se depositaron en la base de datos del GenBank.

\section{RESULTADOS Y DISCUSIÓN}

\section{Aislamiento y obtención de cultivos monoconidiales (cepas)}

Se obtuvieron 439 cepas procedentes de las 84 mazorcas. El 54 \% (237/439) de las cepas provino de semillas sintomáticas y el 46 \% (202/439) de semillas asintomáticas (Cuadro 1); es decir, de una misma mazorca se pueden aislar colonias de Fusarium de ambos tipos de semillas; en consecuencia, es probable que el fitomejorador seleccione germoplasma susceptible a pudrición de la mazorca cuando elige fenotipos aparentemente sanos; es decir, plantas que producen mazorcas en las que coexisten ambos tipos de semilla.

La distribución de las cepas por entidad fue la siguiente: Chiapas $35.6 \%$ [(70 de semillas asintomáticas + 86 de sintomáticas)/439], Estado de México, Chihuahua y
Jalisco 17.3 \% y Guanajuato $12.5 \%$. Este número de aislamientos guarda paralelismo con la frecuencia de mazorcas provenientes de cada entidad: Chiapas $33.3 \%$, Estado de México $16.7 \%$, Guanajuato $12 \%$, Chihuahua y Jalisco 19 \% (Cuadro 1). Lo anterior significa que no hubo una mayor frecuencia de aislamientos entre entidades; sin embargo, como se desconoce la nomenclatura varietal de las mazorcas, persiste la duda de si el número de muestras (mayor en Chiapas que en Guanajuato) se debe a que en la primera entidad existe mayor incidencia de Fusarium que en la segunda.

Dentro de cada entidad federativa no hubo predominancia del número de cepas aisladas de semillas asintomáticas con respecto al de semillas sintomáticas (i.e. Chiapas 70 vs. 86, Chihuahua 38 vs. 38). De éstas, sólo una de las muestras asintomáticas de mazorca (Cuautenango, Tenango del Valle, Estado de México) no presentó micelio (Cuadro 1).

En cuanto a la pigmentación de las cepas (Cuadro 1); el 49.6 \% [i.e., (139 de semillas asintomáticas + 79 de sintomáticas)/439)] fueron blancas; $18.0 \%$ color salmón (con mayor incidencia en Chiapas); 15.5 \% moradas, con mayor incidencia en Chiapas y sin presencia en Guanajuato; 10.5 \% rojas (sin presencia en Chiapas) y 6.4 $\%$ de color violeta, con mayor presencia en el Estado de México y ausentes en Jalisco; sin embargo, al agrupar las cepas en función de la sintomatología se observa que, en general, los colores blanco y salmón están presentes, aunque con diferente frecuencia en semillas sintomáticas y asintomáticas en casi todas las entidades, con excepción de las muestras provenientes de Chihuahua, y los colores violeta y rojo predominan en las semillas sintomáticas del Estado de México y Jalisco. En un estudio sobre la pigmentación de los micelios de Fusarium provenientes de semillas sintomáticas de maíz se observó predominancia del color morado y blanco, mientras que los de semillas asintomáticas fueron de color violeta, blanco o crema (Solano-Báez et al., 2011).

\section{Reconstrucción filogenética de los aislamientos usando el gen TEF-1a}

Con base en los resultados de la amplificación del gen TEF-1a se observó la presencia de amplicones bien definidos de $\sim 650 \mathrm{pb}$ (Figura 1).

El análisis de las secuencias de los 439 aislamientos (202 procedente de semillas asintomáticas y 237 de semillas sintomáticas) indicó la presencia de las especies F. subglutinans (GenBank MN517841 y MN517842), F. temperatum (GenBank MN517843 y MN517844) y F. verticillioides (GenBank MN517845, MN517846 y 


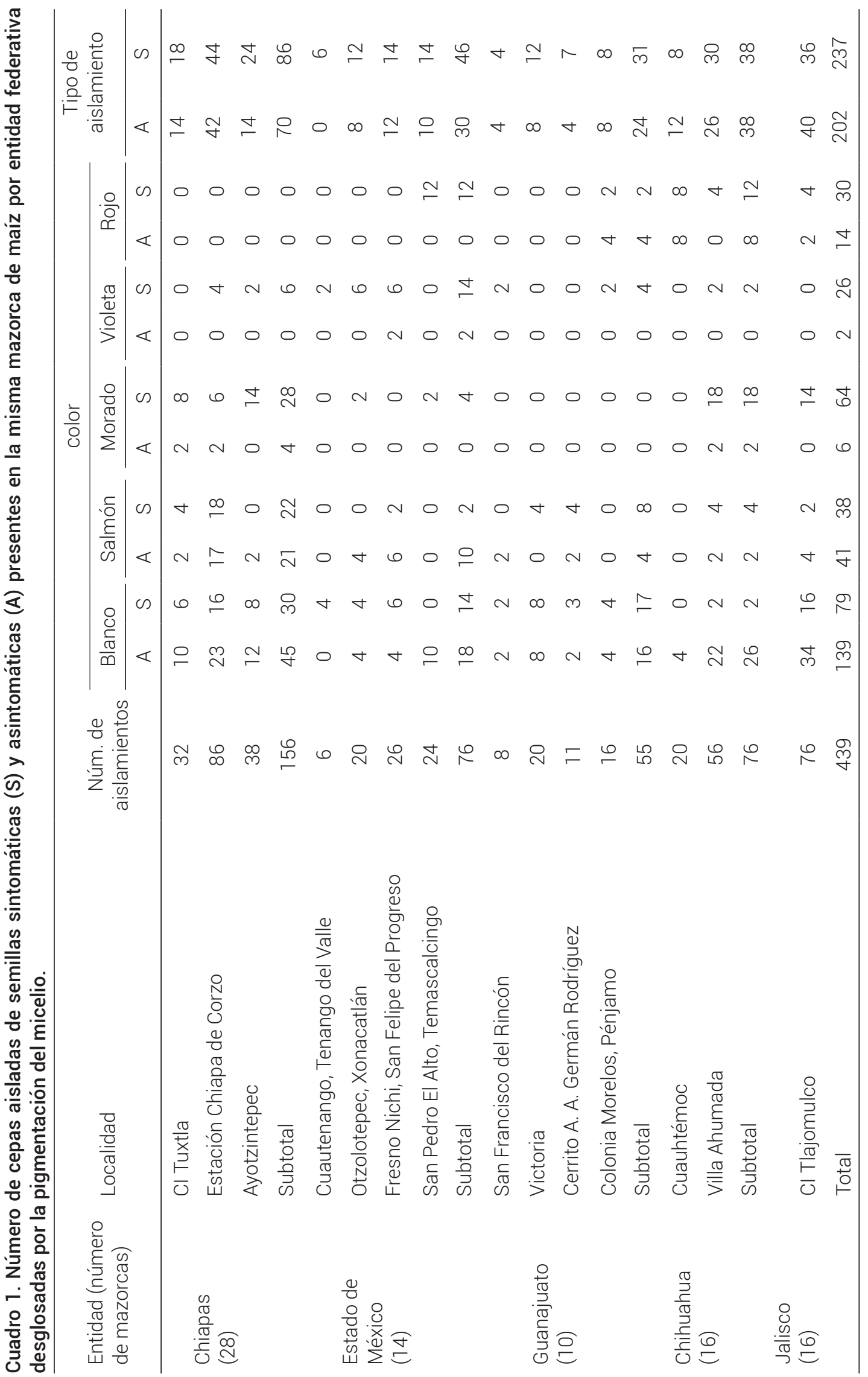




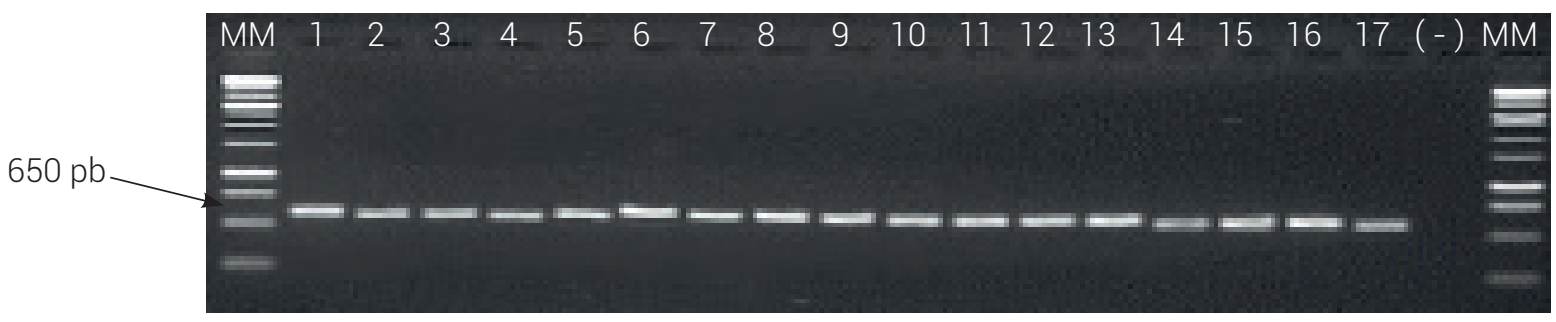

Figura 1. Bandas de 650 pares de bases $(\mathrm{pb})$ correspondientes a la amplificación parcial del factor de elongación de la traducción $1 a$ de Fusarium spp. Carriles 1 a 3: cepas de Chiapas 2.1.1a, 2.2.2s y 3.2.2s; carriles 4 a 6: cepas del Estado de México 26.1.1a, 26.5.1s y 27.3s; carriles 7 a 9: cepas de Guanajuato 32.5.1s, 33.1.1 a y33.5.1s; carriles 10 a 12: cepas de Jalisco 53.2.1s, 55.1.1a y 55.3.1s; carriles 13 a 14: cepas de Chihuahua 33.1.1a y 33.5.1s; carriles 15 a 17: cepas de Sinaloa 21.1.1a, 21.2.1a y 21.4.1s. a: asintomática; s: sintomática; MM: marcador molecular de $1 \mathrm{~kb}$.

MN517847); además, para el caso de F. verticillioides se detectó la presencia del Haplotipo 10 en las muestras procedentes de Chiapas (27 aislamientos de semillas asintomáticas, 32 de sintomáticas), Estado de México (27 de semillas asintomáticas, 42 de sintomáticas), Chihuahua (12 de semillas asintomáticas, 13 de sintomáticas) y Jalisco (23 de semillas asintomáticas, 20 de sintomáticas); y del Haplotipo 11 en Chiapas (11 aislamientos de semillas asintomáticas, 14 de sintomáticas) y en Chihuahua (3 de semillas asintomáticas, 3 de sintomáticas), los que representan un nuevo registro para México (Figura 2), más un grupo no definido en el mismo clado (Figura 3), que corresponden a lo propuesto por Zhang et al. (2016), quienes se basaron en cambios de un solo nucleótido (SNP) en las posiciones 59 a 606 del gen TEF-7a. Los cambios en el Haplotipo 10 corresponden a las posiciones 591 (C/T) y 606 (C/T) (GenBank MN025470) y en el Haplotipo 11 en la posición 606 (C/T) (GenBank MN025471) (Cuadro 2). Otras evidencias de la diversidad genética de las poblaciones de F. verticillioides se han obtenido mediante el uso de microsatélites (Leyva-Madrigal et al., 2017).

Fusarium temperatum es una subpoblación derivada de F. subglutinans, descrita por Scauflaire et al. (2011) dentro del complejo Fusarium fujikuroi, que se caracteriza por incluir especies que producen toxinas que constituyen un peligro para la bioseguridad agrícola, la inocuidad de los alimentos y la salud de las plantas y animales (O'Donnell et al., 2018; Wang et al., 2014). Asimismo, esta especie se ha reportado causando tizón en plántulas, pudrición de tallo y pudrición de mazorca en España (Pintos et al., 2013), Corea del Sur (Shin et al., 2014), Polonia (Czembor et al., 2014), China (Zhang et al., 2014), América del Norte (Lanza et al., 2016) e Italia (Venturini et al., 2016). En México, F. temperatum se ha aislado también de suelo donde se ha cultivado previamente maíz (Robles-Barrios et al., 2015) y F. subglutinans se ha encontrado en Chihuahua, Guanajuato y Estado de México.

En semillas sintomáticas procedentes de razas e híbridos de maíz en los Valles Altos Centrales de México, además de F. temperatum, F. subglutinans y F. verticillioides, se ha demostrado la presencia de F. chlamydosporum, F. napiforme, F. poae y F. pseudonygamai (Morales-Rodríguez et al., 2007; Rivas-Valencia et al., 2011). En semillas procedentes de Sinaloa se obtuvieron 63 aislamientos de F. verticillioides, cuatro de F. andiyazi, dos de F. thapsinum y dos de F. nygamai (Leyva-Madrigal et al., 2015). El mayor número de especies de Fusarium que estos autores mencionan, con respecto al número de especies del mismo género observado en el presente estudio, podría atribuirse a que las mazorcas aquí analizadas fueron producto de programas de mejoramiento genético enfocados a la selección de líneas resistentes a pudrición de mazorca; sin embargo, cuando estas líneas se siembran en localidades con presencia de haplotipos de F. verticillioides diferentes de los que fueron seleccionados, es posible observar el crecimiento miceliar de nuevos linajes.

\section{CONCLUSIONES}

El porcentaje de las cepas de Fusarium aisladas en semillas asintomáticas y sintomáticas de maíz es similar, lo que indica que pueden aislarse colonias de hongos en ambos tipos de semillas cuando se encuentran en una misma mazorca. No hubo predominancia en el número de aislamientos fúngicos entre ambos tipos de semillas en entidad federativa alguna. Las especies de Fusarium identificadas mediante amplificación y secuenciación de la secuencia parcial del gen TEF-1a pertenecen a Fusarium verticillioides Haplotipos 10 y 11, F. subglutinans y $F$. temperatum, miembros del complejo F. fujikuroi. 


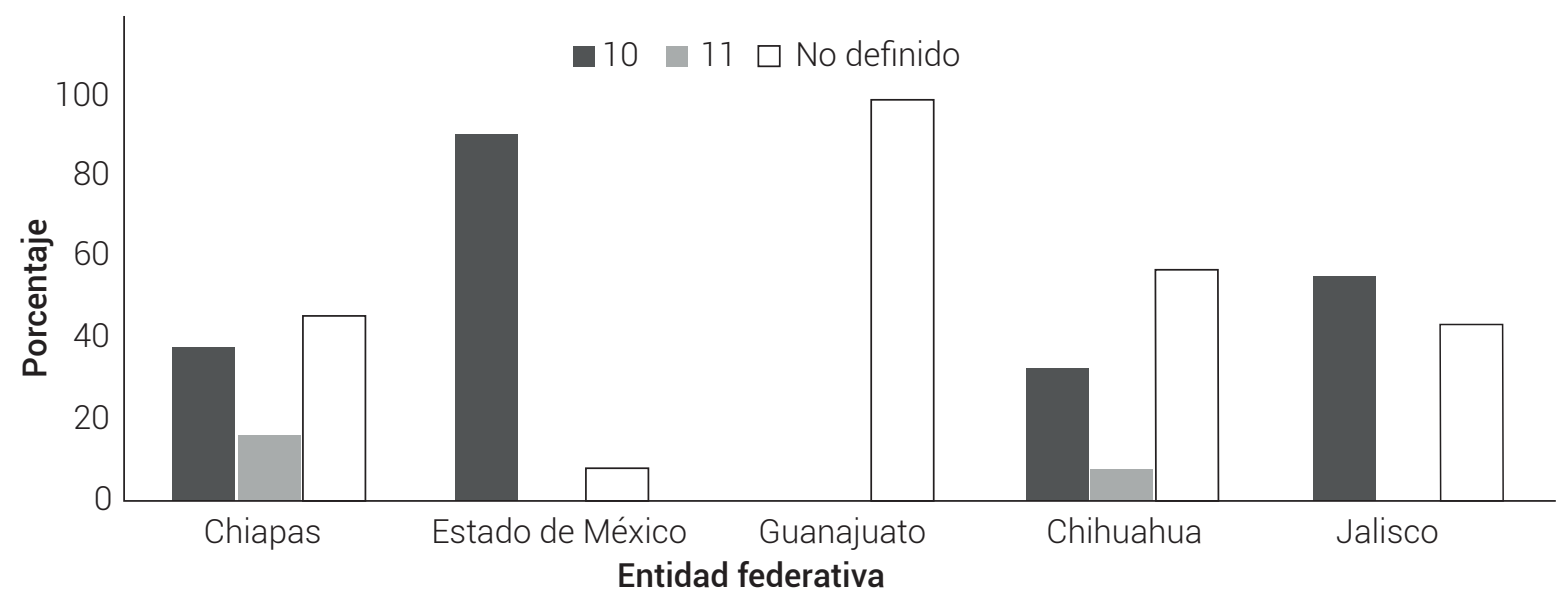

Figura 2. Porcentaje de los Haplotipos 10 y 11 de Fusarium verticillioides aislados de semilla de maíz por entidad federativa. Ambos haplotipos representan nuevos registros para México.

\section{AGRADECIMIENTOS}

Se agradece al Consejo Nacional de Ciencia y Tecnología (CONACYT) por el financiamiento para los estudios de Maestría de la primera autora y al Laboratorio de Investigación de Dupont-Pioneer en Tlajomulco de Zúñiga por proporcionar el material genético y por las facilidades para el aislamiento de las especies de Fusarium. Al Laboratorio de Biotecnología y Patología de Semillas del PREGEP-Producción de Semillas del Colegio de Posgraduados, por el financiamiento parcial para la secuenciación través del proyecto PS17-4011.

\section{BIBLIOGRAFÍA}

Alves A., P. W. Crous, A. Correia and A. J. L. Phillips (2008) Morphological and molecular data reveal cryptic speciation in Lasiodiplodia theobromae. Fungal Diversity 28:1-13.

Briones-Reyes D., F. Castillo-González, J. L. Chávez-Servia, V. H. AguilarRincón, C. de León-García-de Alba y A. Ramírez-Hernández (2015) Respuesta del maíz nativo del altiplano mexicano a pudrición de mazorca, bajo infección natural. Agronomía Mesoamericana 26:73-85, https://doi.org/10.15517/am.v26i1.16922

Crous P. W., D. L. Hawksworth and M. J. Wingfield (2015) Identifying and naming plant-pathogenic fungi: past, present, and future Annual Review of Phytopathology 53:247-267, https://doi org/10.1146/annurev-phyto-080614-120245

Czembor E., Ł. Stępień and A. Waśkiewicz (2014) Fusarium temperatum as a new species causing ear rot on maize in Poland. Plant Disease 98:1001, https://doi.org/10.1094/PDIS-11-13-1184-PDN

Doyle J. J. and J. L. Doyle (1990) Isolation of plant DNA from fresh tissue. Focus 12:13-15.

Edgar R. C. (2004) MUSCLE: multiple sequence alignment with high accuracy and high throughput. Nucleic Acids Research 32:1792-1797, https://doi.org/10.1093/nar/gkh340

FAOSTAT, The Food and Agriculture Organization Corporate Statistical Database (2017) Food and agriculture data. Food and Agriculture Organization of the United Nations. Rome. http://www.fao.org/ faostat/es/\#data/QC/visualize (March 2018)

Geiser D. M. (2004) Practical molecular taxonomy of fungi. In: Advances in Fungal Biotechnology for Industry, Agriculture, and Medicine. J. S. Tkacz and L. Lange (eds.). Springer. Boston, Massachusetts, USA. pp:3-14, https://doi.org/10.1007/978-1-4419-8859-1_1
Geiser D. M., M. M. Jiménez-Gasco, S. Kang, I. Makalowska, N. Veeraraghavan, T. J. Ward, N. Zhang, G. A. Kuldau and K. O'Donnell (2004) FUSARIUM ID v. 1.0: a DNA sequence database for identifying Fusarium European Journal of Plant Pathology 110:473-479, https://doi. org/10.1023/B:EJPP.0000032386.75915.a0

Karlsson I., V. Edel-Hermann, N. Gautheron, M. B. Durling, A. K. Kolseth, C. Steinberg, P. Persson and H. Friberg (2016) Genus-specific primers for study of Fusarium communities in field samples. Applied and Environmental Microbiology 82:491-501, https://doi. org/10.1128/AEM.02748-15

Kumar S., G. Stecher and K. Tamura (2016) MEGA7: molecular evolutionary genetics analysis version 7.0 for bigger datasets. Molecular Biology and Evolution 33:1870-1874, https://doi.org/10.1093/ molbev/msw054

Lanza F. E., D. A. Mayfield and G. P. Munkvold (2016) First report of Fusarium temperatum causing maize seedling blight and seed rot in North America. Plant Disease 100:1019, https://doi org/10.1094/PDIS-11-15-1301-PDN

Leslie J. F. and B. A. Summerell (2006) The Fusarium Laboratory Manual Wiley-Blackwell. Ames, lowa, USA. 388 p.

Leslie J. F. and B. A. Summerell (2013) An overview of Fusarium. In: Fusarium: Genomics, Molecular and Cellular Biology. D. W. Brown and R. H. Proctor (eds.). Caister Academic Press. Norfolk, UK. pp:1-11.

Leyva-Madrigal K. Y., C. P. Larralde-Corona, M. A. Apodaca-Sánchez, F. R. Quiroz-Figueroa, P. A. Mexia-Bolaños, S. Portillo-Valenzuela, J. OrdazOchoa and I. E. Maldonado-Mendoza (2015) Fusarium species from the Fusarium fujikuroi species complex involved in mixed infections of maize in northern Sinaloa, Mexico. Journal of Phytopathology 163:486-497, https://doi.org/10.1111/ jph. 12346

Leyva-Madrigal K. Y., E. Sandoval-Castro, C. L. Calderón-Vázquez, C. P. Larralde-Corona and I. E. Maldonado-Mendoza (2017) Pathogenic and genetic variability of Fusarium verticillioides from maize in northern Mexico. Canadian Journal of Plant Pathology 39:486496, https://doi.org/10.1080/07060661.2017.1378726

Mancini V., S. Murolo and G. Romanazzi (2016) Diagnostic methods for detecting fungal pathogens on vegetable seeds. Plant Pathology 65:691-703, https://doi.org/10.1111/ppa.12515

Morales-Rodríguez I., M. J. Yañez-Morales, H. V. Silva-Rojas, G. García-de-losSantos and D. A. Guzmán-de-Peña (2007) Biodiversity of Fusarium species in Mexico associated with ear rot in maize, and their identification using a phylogenetic approach. Mycopathologia 163:31-39, https://doi.org/10.1007/s11046-006-0082-1

O'Donnell K., H. I. Nirenberg, T. Aoki and E. Cigelnik (2000) A multigene phylogeny of the Gibberella fujikuroi species complex: detection of additional phylogenetically distinct species. Mycoscience 41:61-78, https://doi.org/10.1007/BF02464387 


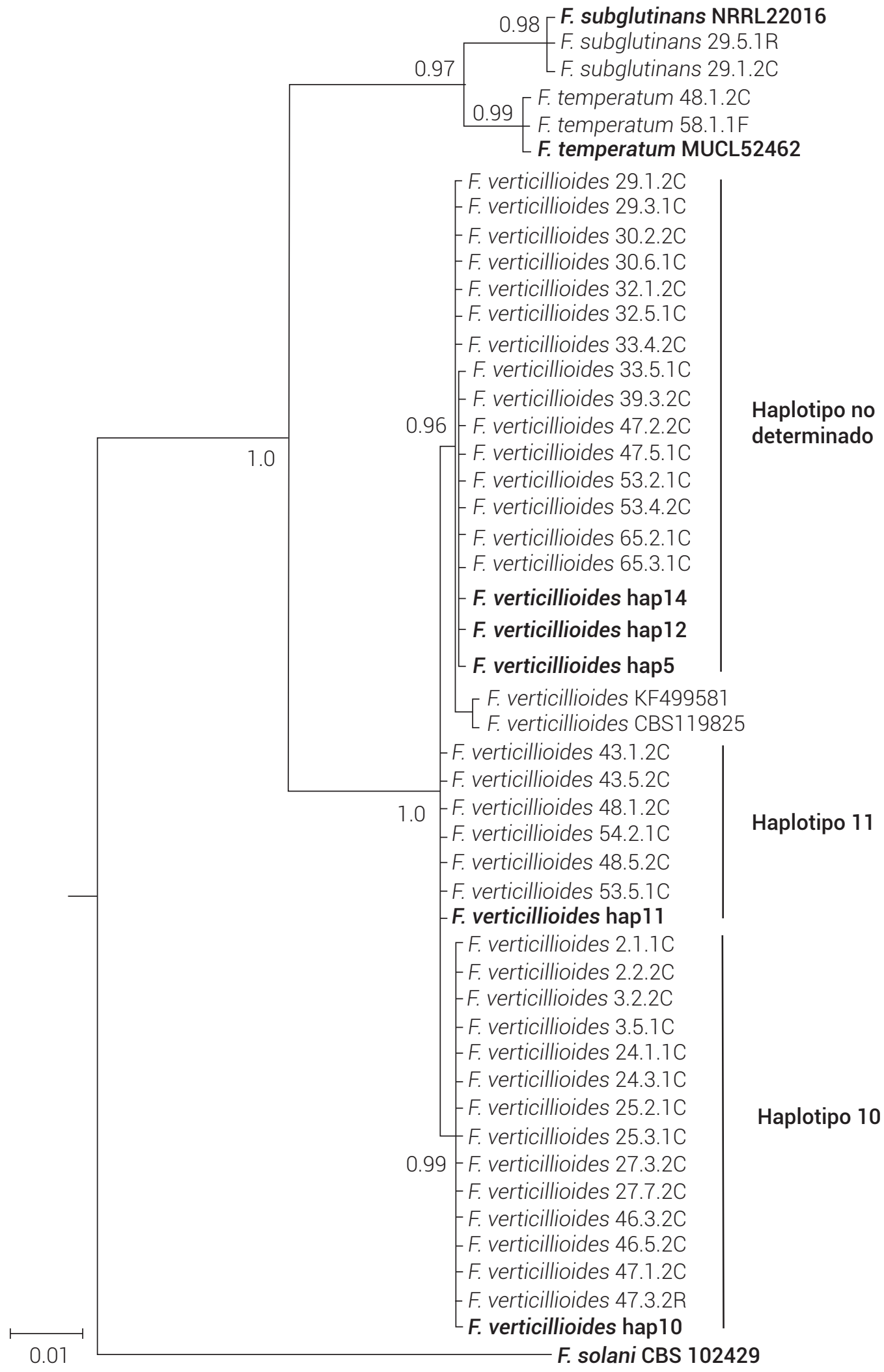

Figura 3. Árbol filogenético construido mediante inferencia bayesiana con secuencias parciales del factor de elongación de la transcripción $7 a$, representativas de los Haplotipos 10 y 11 de Fusarium verticillioides. Fusarium solani cepa CBS 10229 se incluyó como grupo externo. La barra inferior (0.01) indica sustituciones por sitio. 
Cuadro 2. Ubicación de los cambios en un solo nucleótido en la secuencia parcial del factor de elongación de la traducción 1a que permitieron la diferenciación de haplotipos de Fusarium verticillioides.

\begin{tabular}{|c|c|c|c|c|c|c|c|c|c|c|c|c|c|c|}
\hline \multirow{3}{*}{ Haplotipo } & \multicolumn{14}{|c|}{ Posición y tipo de nucleótido ${ }^{+}$} \\
\hline & 59 & 74 & 81 & 124 & 129 & 230 & 246 & 306 & 322 & 356 & 381 & 425 & 591 & 606 \\
\hline & $\mathrm{C}$ & $\mathrm{C}$ & A & G & $\mathrm{C}$ & $\mathrm{C}$ & A & A & $\mathrm{C}$ & $\mathrm{C}$ & A & $\mathrm{C}$ & $\mathrm{C}$ & $\mathrm{C}$ \\
\hline 1 & G & . & . & . & . & . & . & . & . & . & $T$ & . & . & . \\
\hline 2 & & & & A & T & & & & & & . & & & \\
\hline 3 & A & . & . & & . & . & & & . & & T & . & . & \\
\hline 4 & & . & & A & T & A & & & . & & & . & . & \\
\hline 5 & . & . & . & & . & . & & . & . & . & & . & . & \\
\hline 6 & . & . & . & & . & . & & . & . & . & $\mathrm{T}$ & . & . & \\
\hline 7 & & . & . & & . & . & & G & G & & & G & . & \\
\hline 8 & . & . & . & & . & . & & G & G & & & . & . & \\
\hline 9 & & & & & & & . & & & $\mathrm{T}$ & & & & . \\
\hline 10 & & . & & & . & . & & . & . & & & . & $\mathrm{T}$ & $\mathrm{T}$ \\
\hline 11 & & . & & & & & & & & & & & & $\mathrm{T}$ \\
\hline 12 & . & . & C & . & . & . & & . & & & . & . & . & \\
\hline 13 & . & . & & . & . & . & C & . & . & & . & . & $\mathrm{T}$ & $\mathrm{T}$ \\
\hline 14 & & A & . & A & $\mathrm{T}$ & . & & & & & . & . & . & \\
\hline
\end{tabular}

${ }^{\dagger}$ Haplotipos 1 al 14, descritos por Zhang et al. (2016).

O'Donnell K., T. J. Ward, V. A. R. G. Robert, P. W. Crous, D. M. Geiser and S. Kang (2015) DNA sequence-based identification of Fusarium: current status and future directions. Phytoparasitica 43:583595, https://doi.org/10.1007/s12600-015-0484-z

O'Donnell K., S. P. McCormick, M. Busman, R. H. Proctor, T. J. Ward, G. Doehring, D. M. Geiser, J. F. Alberts and J. P. Rheeder (2018) Marasas et al. 1984 "Toxigenic Fusarium species: identity and mycotoxicology" revisited. Mycologia 110:1058-1080, https://doi.org/10.1080/0 0275514.2018 .1519773

Pintos V. C., O. Aguín C., M. Chaves P., V. Ferreiroa M., M. J. Sainz 0., J. Scauflaire, F. Munaut, M. J. Bande C. and J. P. Mansilla V. (2013) First report of Fusarium temperatum causing seedling blight and stalk rot on maize in Spain. Plant Disease 97:1252, https://doi. org/10.1094/PDIS-02-13-0167-PDN

Raja H. A., A. N. Miller, C. J. Pearce and N. H. Oberlies (2017) Fungal identification using molecular tools: a primer for the natural products research community. Journal of Natural Products 80:756-770, https://doi.org/10.1021/acs.jnatprod.6b01085

Rivas-Valencia P., J. Virgen-Vargas, I. Rojas M., A. Cano S. y V. Ayala E. (2011) Evaluación de pudrición de mazorca de híbridos de maíz en Valles Altos. Revista Mexicana de Ciencias Agrícolas 2:845-854.

Robles-Barrios K. F., M. G. Medina-Canales, A. V. Rodríguez-Tovar and N. 0. Pérez (2015) Morphological and molecular characterization, enzyme production and pathogenesis of Fusarium temperatum on corn in Mexico. Canadian Journal of Plant Pathology 37:495505, https://doi.org/10.1080/07060661.2015.1113445

Ronquist F., M. Teslenko, P. van der Mark, D. L. Ayres, A. Darling, S. Höhna, B. Larget, L. Liu, M. A. Suchard and J. P. Huelsenbeck (2012) MrBayes 3.2: efficient bayesian phylogenetic inference and model choice across a large model space. Systematic Biology 61:539-542, https://doi.org/10.1093/sysbio/sys029

Scauflaire J., M. Gourgue and F. Munaut (2011) Fusarium temperatum sp. nov. from maize, an emergent species closely related to Fusarium subglutinans. Mycologia 103:586-597, https://doi org/10.3852/10-135
Shin J. H., J. H. Han, J. K. Lee and K. S. Kim (2014) Characterization of the maize stalk rot pathogens Fusarium subglutinans and F. temperatum and the effect of fungicides on their mycelial growth and colony formation. The Plant Pathology Journal 30:397-406, https://doi.org/10.5423/PPJ.0A.08.2014.0078

SIAP, Servicio de Información Agropecuaria y Pesquera (2016) Anuario estadístico de la producción agrícola. Secretaría de Agricultura Ganadería, Desarrollo Rural, Pesca y Alimentación. Ciudad de México. https://nube.siap.gob.mx/cierreagricola/ (Abril 2016).

Solano-Báez A. R., C. De León-García De Alba, G. Valdovinos-Ponce, H. V. Silva-Rojas y L. Soto-Rojas (2011) La pigmentación de Fusarium verticillioides (Sacc.) como factor de virulencia en plántulas de maíz. Agronomía Mesoamericana 22:297-307.

Tavaré S. (1986) Some probabilistic and statistical problems in the analysis of DNA sequences. In: Lectures on Mathematics in the Life Sciences. DNA Sequence Analysis. Vol. 17. Some Mathematical Questions in Biology. R. M. Miura (ed.). American Mathematical Society. Providence, Rhode Island, USA. pp:5786.

Tsedaley B. (2015) Review on seed health tests and detection methods of seedborne diseases. Journal of Biology, Agriculture and Healthcare 5:176-184.

Venturini G., S. L. Toffolatti, A. Passera, R. Pilu, F. Quaglino and P. Casati (2016) First report of Fusarium temperatum causing ear rot on maize in Italy. Journal of Plant Pathology 98:686, https://doi. org/10.4454/JPP.V98I3.016

Walcott R. R. (2003) Detection of seedborne pathogens. HortTechnology 13:40-47, https://doi.org/10.21273/HORTTECH.13.1.0040

Wang J. H., J. B. Zhang, H. P. Li, A. D. Gong, S. Xue, R. S. Agboola and Y. C. Liao (2014) Molecular identification, mycotoxin production and comparative pathogenicity of Fusarium temperatum isolated from maize in China. Journal of Phytopathology 162:147-157, https://doi.org/10.1111/jph.12164

Wigmann É. F., J. Behr, R. F. Vogel and L. Niessen (2019) MALDI-TOF MS fingerprinting for identification and differentiation of species within the Fusarium fujikuroi species complex. Applied 
Microbiology and Biotechnology 103:5323-5337, https://doi. org/10.1007/s00253-019-09794-z

Young K. J. and S. P. Long (2000) Crop ecosystem responses to climatic change: maize and sorghum. In: Climate Change and Global Crop Productivity. K. R. Reddy and H. F. Hodges (eds.). CABI Publishing. Wallingford, UK. pp:107-131

Zhang Z., S. Schwartz, L. Wagner and W. Miller (2000) A greedy algorithm for aligning DNA sequences. Journal of Computational Biology 7:203-214, https://doi.org/10.1089/10665270050081478
Zhang H., B. Brankovics, W. Luo, J. Xu, J. S. Xu, C. Guo, ... and C. Waalwijk (2016) Crops are a main driver for species diversity and the toxigenic potential of Fusarium isolates in maize ears in China. World Mycotoxin Journal 9:701-715, https://doi.org/10.3920/ WMJ2015.2004

Zhang H., W. Luo, Y. Pan, J. Xu, J. S. Xu, W. Q. Chen and J. Feng (2014) First report of Fusarium temperatum causing Fusarium ear rot on maize in Northern China. Plant Disease 98:1273, https://doi. org/10.1094/PDIS-02-14-0124-PDN 